\title{
LOGÍSTICA DE DISTRIBUIÇÃO E CONTROLE DE ESTOQUES EM UMA DISTRIBUIDORA DE MEDICAMENTOS.
}

\section{DISTRIBUTION LOGISTIC AND SUPPLIES CONTROL IN A MEDICINE DELIVERER}

\author{
JOSMÁRIA LIMA RIBEIRO DE OLIVEIRA \\ Mestranda em Administração pela Universidade Federal de Lavras - UFLA/MG. Bacharel em \\ Ciências Contábeis pela UFMG. josmariadeoliveira@terra.com.br. Fone: (31) 9619- \\ 6337/3444-3737. Rua Silveira, 62/306 ${ }^{\mathrm{A}}$ Floresta, Belo Horizonte/MG - 31.140.000.
}

\section{SIDNEY LINO DE OLIVEIRA}

Mestre em Administração pela PUC/MG. Master of Business Administration - MBA Executivo Internacional em Marketing - Fundação Getúlio Vargas / Ohio University. Especialista em Pedagogia Empresarial pela Universidade Estadual de Minas Gerais UEMG. Bacharel em Administração pela PUC/MG. sidneylino@terra.com.br. Fone: (31) 9951-1072/3444-3737. Rua Silveira, 62/306 ${ }^{\mathrm{A}}$ Floresta, Belo Horizonte/MG - 31.140.000.

\section{Resumo}

Este artigo apresenta uma análise da logística de distribuição e controle de estoques de uma distribuidora de medicamentos. Para tanto, são enfocadas as formas de distribuição e controle de estoque além da relevância do trabalho de marketing ligado à logística para obter a conquista e satisfação do cliente. Este estudo de caso foi desenvolvido em uma distribuidora de medicamentos situada em Juiz de Fora/MG que atende à região da Zona da Mata e o interior do estado do Rio de Janeiro. Para a realização deste estudo de caso utilizou-se a coleta de dados por meio de entrevista semi-estruturada, levantamento documental e a observação não-participante. Como resultados, identificou-se que a distribuidora utiliza o sistema de distribuição um para muitos, organiza o estoque de produtos por produto e não terceiriza o serviço de entrega. A distribuidora necessita da utilização de um sistema de informação que permita melhor integração entre os setores da empresa.

\section{Palavras-Chave}

Logística, estoque, distribuidora de medicamentos.

\begin{abstract}
This paper approaches about the distribution logistic and supplies control of a medicine deliverer. For in such a way, the forms of distribution and supply control beyond the relevance of the work of on marketing to the logistic one getting the conquest and satisfaction of the customer are focused. This study of case it was developed in a situated medicine deliverer in Juiz de Fora/MG that takes care of to the region of the Zone of Mata and the country side of the state of Rio de Janeiro. For the accomplishment of this study of qualitative case was used collects it of data by means of half-structuralized interview and the comment
\end{abstract}


not-participant. As results, it was identified that the deliverer uses the system of distribution one for many, organizes the supply of products for product and not concession the delivery service. The deliverer needs the use of an information system that allows integration better enters the sectors of the company.

\section{Key Words}

Logistic, supply, medicine deliverer.

\section{Introdução}

No setor de distribuição farmacêutica a concorrência entre empresas se concentra no campo da logística. O produto distribuído, ou seja, os remédios são caracterizados como commodity, pois os mesmos medicamentos podem ser adquiridos em outros distribuidores. Atualmente, é muito raro existirem distribuidores exclusivos de laboratórios no mercado. Portanto, além do produto fornecido, as distribuidoras oferecem serviços diferenciados e atrativos. Entende-se que esta diferenciação pode ser alcançada por intermédio da aplicação do marketing na logística, que consiste em oferecer alguns serviços que agradam aos clientes, por meio da disponibilidade do produto, pronta entrega e atendimento correto dos pedidos.

Os canais de distribuição contemplam atacadistas e varejistas. Neste artigo, são considerados atacadistas os distribuidores, e varejistas as farmácias. A diferença entre estes, para PARENTE (2000), consiste no processo de venda. O atacado vende para clientes institucionais, que compram produtos e serviços, para revendê-los para suas atividades profissionais. Já os varejistas, compram, recebem, e estocam produtos de fabricantes ou atacadistas para oferecer aos consumidores finais a conveniência de tempo e lugar para aquisição de produtos.

Muitas transformações vêm ocorrendo na distribuição dos produtos farmacêuticos no Brasil, que hoje é muito diferente do cenário nos anos 70. Antes, os laboratórios por meio do PVC (Propagandista-Vendedor-Cobrador), vendiam diretamente para os pontos de venda. Nesta época, a figura do distribuidor era bem discreta, pois a quantidade de farmácias permitia que os laboratórios pudessem atender diretamente os clientes finais. Com o aumento do número de farmácias no país, foi inviabilizada a venda direta dos laboratórios para esses estabelecimentos, afinal, o custo da operação logística, especialmente para regiões mais distantes, é alto. E a indústria farmacêutica assumia todos os riscos da distribuição, como, por exemplo, a inadimplência das farmácias. 
A partir desse cenário, o número de distribuidores começou a aumentar, embora tenha ocorrido uma atuação regionalizada. Geralmente, a rede de distribuidores era constituída de ex-funcionários dos próprios laboratórios, que se desligavam da empresa e adquiriam a representação de vendas dos medicamentos, desenvolvendo uma nova atividade profissional. No Brasil existem grandes distribuidoras que atuam em todo o território nacional, mas existem distribuidoras que atuam apenas regionalmente com uma estrutura limitada em relação às demais, podendo ser classificada como pequena empresa, caso da distribuidora em estudo.

As grandes redes varejistas são os maiores inimigos do distribuidor independente, pois estas têm maior presença nos grandes centros urbanos, enquanto os distribuidores atuam mais nas cidades menores e na periferia dos grandes centros urbanos. Diante deste cenário, percebe-se que os distribuidores servem milhares de clientes e o seu sucesso depende da capacidade de realizar essas vendas, e fazer as entregas a custos baixos. Uma particularidade deste ramo de atuação diz respeito a perecebilidade e a sazonalidade que alguns medicamentos apresentam.

Apesar da expressiva concorrência, a maior parte das inovações introduzidas por grandes distribuidoras de medicamentos no Brasil foca o caráter logístico e envolvem processos de movimentação de produtos, vendas a baixo custo, distribuição e controles. Os distribuidores ainda conseguem manter o seu domínio no mercado de medicamentos, porque este é pulverizado e as farmácias são muito numerosas.

Sistemas logísticos flexíveis e dinâmicos, que se concentram nos requisitos dos clientes, podem proporcionar às empresas vantagens competitivas tanto sobre concorrentes estabelecidos como sobre novos participantes do mercado. Para uma distribuidora de medicamentos conseguir posicionamento no mercado é necessário atrair clientes e mantê-los. As distribuidoras não têm expressiva margem de negociação com relação a preço e prazo, e dificilmente conseguem se diferenciar neste sentido, portanto, estas precisam atingir diferenciais competitivos por meio da atividade de logística.

Em algumas distribuidoras de medicamentos, atualmente, os remédios já recebem um selo de segurança que causa avaria na embalagem caso se tente retirá-lo. Este selo identifica que o medicamento é de uma determinada distribuidora. Todos os lotes são registrados em computador. Assim é possível saber quando e para quem foram vendidos. Os caminhões e peruas de entrega são monitorados por satélite e rádio. Só isso, no entanto, não basta para dar- 
lhes visibilidade e transparência. Cada vez mais as distribuidoras têm implantado softwares de gestão, que também servem como ferramenta mercadológica contra a concorrência. Eles geram milhares de informações sobre os lojistas que, agrupadas por regiões ou pelo consumo de produtos, são usadas como moeda de troca com os laboratórios.

Este artigo tem o objetivo de identificar por meio de estudo de caso quais são os processos logísticos e as formas de controle de estoque de uma distribuidora farmacêutica situada em Juiz de Fora/MG que atende à região da Zona da Mata e o interior do estado do Rio de Janeiro. No decorrer deste artigo serão denominados clientes, as farmácias que adquirem produtos da distribuidora; sendo assim, o consumidor dos remédios, ou seja, o paciente, será denominado de consumidor final.

Este trabalho está dividido em quatro seções. A primeira seção diz respeito aos esclarecimentos teóricos que permitiram a análise do ambiente; esta seção aborda a logística de marketing e a agregação de valor do cliente, e também a logística de distribuição e o controle estoque. A segunda seção descreve sobre os procedimentos metodológicos utilizados que permitiram a investigação do objeto de estudo. A terceira seção apresenta os resultados obtidos a partir da análise da distribuidora e apresenta algumas discussões sobre os métodos utilizados. A última seção apresenta a análise conclusiva do trabalho que retoma os pontos mais marcantes do trabalho e apresenta sugestões e propostas para novas pesquisas.

\section{Logística de distribuição e controle de estoque}

A vantagem de valor vem da satisfação do cliente com serviços básicos, como qualidade e disponibilidade. Portanto, a vantagem de custo pode ser obtida por intermédio do aumento de produtividade, diluição de custos fixos e administração da logística, que permite a redução de custos. Que valor tem um produto ou serviço certo, mas que não está disponível para o cliente no momento certo? Para REIS (2002), o valor pode ser oferecido de duas formas ao cliente: “(...) por meio de benefícios intrínsecos, como características físicas e desempenho (adequação das funções, facilidade de uso, qualidade, durabilidade, etc.), e benefícios intangíveis, como serviço (disponibilidade, atendimento etc.), imagem da marca e da empresa e outros".

A logística orientada para o cliente permite conquistar vantagens competitivas, concentrando o foco cuidadosamente na logística de valor e cultivando relacionamentos lucrativos com o 
cliente. Trata-se de um método de usar a logística para ir além da diferenciação de produtos, chegando à diferenciação de serviços, conforme afirma ROSENBLOOM (2002). Esta importância é dada principalmente no setor atacadista, embora muitas vezes relegada para segundo plano, o que o eleva ao nível estratégico, ao lado da prestação de serviços. Além disso, a logística transforma aspectos fundamentais da concorrência, como preço e características do produto, em excelência de serviço e valor para o cliente.

O nível de serviço logístico contempla a qualidade com que o fluxo de bens e serviços é gerenciado e o desempenho oferecido pelos fornecedores aos seus clientes para assegurar sua fidelidade. Sendo assim, como o nível de serviço logístico está associado aos custos de prover esse serviço, o planejamento da movimentação de bens e serviços deve iniciar-se com as necessidades de desempenho dos clientes no atendimento de seus pedidos (BALLOU, 1993).

A cooperação e a confiança entre distribuidores e farmácias, ou seja, na cadeia de suprimento ajudam a melhorar o desempenho porque conquista um alinhamento mais natural entre incentivos e objetivos, eliminam a duplicação de tarefas ou esforços, compartilham informações detalhadas sobre vendas e produção e permitem medidas gerenciais orientadas por ações (CHOPRA e MEINDL, 2003).

HARRISON e HOECK (2003) afirmam que a partir do relacionamento entre as partes, existe a possibilidade de que seja implantado o modelo Just in Time 2, que coloca os processos os processos do varejo e do distribuidor mais próximos. No modelo citado, elimina-se o comprador e o vendedor do relacionamento cliente-fornecedor, promovendo, assim, uma maior comunicação entre as partes, pois um funcionário do fornecedor substitui o escritório de compras do varejo, reduzindo custos para este. Percebe-se que a partir da utilização de sistemas integrados, torna-se viável inclusive a solicitação de compras via sistema, o que otimiza o processo logístico.

Para BALLOU (1993), nem todo cliente precisa ou deve ser tratado da mesma forma que outros clientes ou categorias de clientes, para tanto, é preciso compreender as necessidades de serviço dos clientes. Quando diferenças nos níveis de serviço são conhecidas, pode-se projetar sistemas de distribuição mais apropriados, e o resultado consiste em uma distribuição mais eficaz, com menores custos e a satisfação do cliente. 
Para KOTLER (2000), a logística de mercado corresponde ao planejamento, à implementação e ao controle dos fluxos físicos de produtos entre os pontos de origem e de destino, com o objetivo de atender às exigências dos clientes. COUGHLAN et al. (2002) afirmam que a logística envolve o processamento e o rastreamento de bens durante o armazenamento, o controle de estoque, o transporte, a documentação alfandegária e a entrega para os clientes.

CHRISTOPHER (1997:2) conceitua que o conceito principal de logística é caracterizado como “(...) processo de gerenciar estrategicamente a aquisição, movimentação e armazenagem de materiais, peças e produtos acabados (e os fluxos de informações correlatas) por meio da organização e seus canais de marketing, de modo a poder maximizar as lucratividades presentes e futuras por meio do atendimento dos pedidos a baixo custo".

O fornecimento de serviços de logística representa uma área ampla e inexplorada para a criação de valor agregado mais alto nas transações de compra. Quando compram, os clientes adquirem mais do que o produto básico, o qual é definido por (KOTLER e ARMSTRONG, 1999:190) “(...) o que o consumidor está realmente comprando? (...) o produto básico é o centro do produto total. Consiste em serviços que solucionam problemas ou em benefícios básicos que os consumidores buscam na compra". Eles também adquirem o pacote de serviços que acompanha o produto. Esse pacote inclui componentes como flexibilidade de preço, promoções, acordos, descontos, crédito e condições de pagamento, apoio de merchandising, serviço pós-venda e pós-entrega, e serviços de logística.

Para a transação de mercadorias, deve-se considerar critérios como velocidade, freqüência, confiabilidade, capacidade, disponibilidade, rastreabilidade e custo (KOTLER, 2000). Existem dois tipos de sistema de distribuição, segundo NOVAES (2001): 1) Um para um (o veículo é totalmente carregado no depósito da fábrica e transporta para um outro ponto de destino); 2) Um para muitos (o veículo é carregado no depósito da fábrica com mercadorias destinadas a diversas lojas ou clientes, e executa um roteiro de entregas predeterminado).

Para o gerenciamento logístico deve-se considerar a estrutura dos sistemas de distribuição, para que estes sejam capazes de atender de forma econômica os mercados geograficamente distantes das fontes de distribuição, oferecendo níveis de serviço cada vez mais altos em termos de disponibilidade de estoque e tempo de atendimento. Neste contexto, a atenção se volta para as instalações de armazenagem e como elas podem contribuir para atender de forma eficiente as metas estabelecidas de nível de serviço. A funcionalidade destas 
instalações dependerá da estrutura de distribuição adotada pela empresa. O centro de distribuição tem um papel fundamental dentro da logística, centralizando o estoque a fim de obter vantagens econômicas e de eficiência (RODRIGUES e PIZZOLATO, 2003). Os métodos de armazenagem e endereçamento são apresentados na sub-seção a seguir.

A redução do custo do projeto do sistema logístico é considerada como um objetivo da logística na empresa para BALLOU (2001). SLACK et al. (1996) consideram que os custos logísticos podem ser divididos em dois tipos. O primeiro consiste nos custos operacionais, que são os custos que variam diretamente com a variação do nível da atividade. O segundo são os custos de capital, que ocorrem apenas uma vez e que não mudam com as variações normais nos níveis de atividades. BALLOU (2001) apresenta esta mesma divisão dos custos, no entanto, os classifica em custos fixos e variáveis.

\section{$\underline{\text { Controle de estoque }}$}

Em uma distribuidora de medicamentos o controle de estoques é importante para a atuação desta no mercado. O controle de estoques tem o objetivo de minimizar o capital total investido em estoques. Para tanto, faz-se necessário que as políticas de estoque sejam adequadamente definidas pela empresa determinando qual o tempo de entrega dos produtos ao cliente; até que nível deverá flutuar os estoques para atender uma alta ou baixa das vendas ou uma alteração de consumo; e definição da rotatividade de estoques. Portanto, os problemas de dimensionamento de estoque residem na relação entre capital investido, disponibilidade de estoques, custos incorridos, e demanda, DIAS (1995). No intuito de minimizar os custos, BALLOU (1993) expressa que as empresas estabelecem uma política de tamanho mínimo de pedido para tentar atingir algumas economias de escala em transporte e atendimento, pois esta política ainda permite a redução do número de pedidos necessários para um dado volume de negócios.

Por meio de uma eficiente administração da armazenagem, VERÍSSIMO e MUSETTI (2003) consideram que é possível: "a redução de estoques, a otimização da movimentação e da utilização do armazém, o atendimento rápido ao cliente e à linha produtiva, a redução do índice de material obsoleto, precisão e acuracidade das informações". Com estas possibilidades ocorrem: a diminuição dos custos, a melhoria da integração do processo de armazenagem com os demais processos da organização e a melhoria do atendimento ao cliente. 
Para SIMCHI-LEVI et al. (2003), as empresas têm necessidade de manter estoque porque precisam proteger-se contra mudanças inesperadas e situações de incertezas. Os autores consideram dois aspectos importantes no gerenciamento de estoque: 1) previsão de demanda; 2) cálculo das quantidades de pedidos de reposição de estoques. BALLOU (1993) considera motivos para a empresa manter estoques: a proteção de incertezas na demanda e no tempo de ressuprimento; a proteção contra aumento de preços; a permissão de economias de escala nas compras e no transporte; e a segurança contra contingências.

Segundo SLACK et al. (1996), estoque é a acumulação armazenada de recursos materiais em um sistema de transformação, sendo utilizado para descrever qualquer recurso armazenado. $\mathrm{O}$ estoque é criado para compensar diferenças de ritmo entre fornecimento e demanda. Entre os tipos de estoque, observam-se quatro, sendo eles:

- Estoque isolador, ou também chamado de estoque de segurança. O propósito deste estoque é compensar as incertezas inerentes a fornecimento e demanda. Este nível mínimo de estoque existe para cobrir a possibilidade da demanda vir a ser maior do que a esperada durante o tempo gasto na entrega dos bens.

- Estoque de ciclo, este tipo de estoque ocorre porque um ou mais estágios na operação não podem fornecer todos os itens que produzem simultaneamente.

- Estoque de antecipação é utilizado para compensar diferenças de ritmo de fornecimento e demanda. Comumente usado quando as flutuações de demanda são significativas, mas relativamente previsíveis.

- Estoques no canal (de distribuição), este tipo de estoque existe porque o material não pode ser transportado instantaneamente entre o ponto de fornecimento e o ponto de demanda.

As decisões de estoque baseiam-se nas questões que facilitam as decisões dos gerentes no diaa-dia. Este procedimento envolve as atividades desde a chegada do produto, incluindo operações de armazenamento, emissão de pedidos, envio de mercadorias e controle da movimentação. Para SLACK et al. (1996), no gerenciamento do sistema de estoques, os gerentes de produção estão envolvidos em três principais tipos de decisões, sendo eles: 1) quanto pedir (cada vez que um pedido de abastecimento é colocado, de que tamanho ele deve ser?); 2) quando pedir (em que momento ou nível de estoque, o pedido de reabastecimento deve ser colocado?); 3) como controlar o sistema? (que procedimentos e rotinas devem ser implantados para ajudar a tomar estas decisões). 
A determinação de quando pedir mais produtos para o estoque utiliza freqüentemente a Curva Dente de Serra, com o estoque mínimo, expressa por SLACK et al. (1996) e DIAS (1995). Com o uso desta curva, é possível identificar quando deve ser feito o pedido, considerando o tempo de reposição e a quantidade média de venda do produto dentro de um determinado período de tempo. Considera-se que o estoque mínimo é importante para que a empresa possa atender a todas as solicitações de produtos feitos pelos clientes; pois se for solicitado um produto à distribuidora e esta não o conter no estoque, o cliente imediatamente se dirigirá a outra distribuidora para solicitar o produto, que o fará a entrega de imediato. BALLOU (1993) enfoca que a quantidade a ser comprada também sofre influência da demanda, que pode ser permanente, sazonal, irregular, em declínio e derivada.

A operação de arranjo físico é de grande importância para a agilidade da empresa em suas atividades. Os cuidados a serem tomados para a movimentação do estoque levam em consideração a natureza do material movimentado (características físicas e químicas) e as características de volume e variedade de uma operação, segundo SLACK et al. (1996) e DIAS (1995). A decisão sobre qual arranjo específico escolher é influenciada por um entendimento correto das vantagens e desvantagens de cada tipo. Para SLACK et al. (1996), o arranjo físico pode ser estruturado em: 1) Posicional (preocupa-se com a localização física dos recursos transformadores, conhecidos como centros de recursos); 2) Por processo (projetada por uma combinação de intuição, bom senso, processos de tentativa e erro aplicados sistematicamente); 3) Celular (representa um compromisso entre a flexibilidade do arranjo físico por processo e a simplicidade do arranjo físico por produto); e 4) Por produto (arranjar os recursos assimilando as necessidades de processamento do produto ou serviço produzido).

Para a armazenagem das mercadorias no depósito utiliza-se, na maioria das vezes, a separação por estantes identificadas por letras, com prateleiras que também devem ser identificadas por letras, e escaninhos (intervalo entre a coluna da estante e a prateleira) que devem ser identificados por número, DIAS (1995). Este autor apresenta dois critérios de localização de material: 1) sistema de estocagem fixo (define-se que apenas um tipo de material pode ser estocado em um determinado local); 2) sistema de estocagem livre (não existem locais fixos de armazenagem, a não ser para produtos de estocagem especial).

Segundo DIAS (1995), a classificação dos produtos no depósito consiste em ordenar o produto segundo critérios adotados, agrupando-o de acordo com a semelhança, sem, contudo, 
causar confusão ou dispersão no espaço e alteração na qualidade. Os sistemas de codificação mais comumente utilizados são: alfabético, alfanumérico, e numérico.

Lidar com vários itens estocados, fornecidos por diversos fornecedores torna a tarefa de operações complexa e dinâmica. Para que os sistemas de controle e análise de estoque sejam eficazes existe a necessidade de operar em duas frentes: discriminar os diferentes itens estocados para que se aplique um grau de controle a cada item; investir em um sistema de processamento de informação que possa lidar com seus particulares conjuntos de circunstâncias de controle de estoque. As principais funções dos sistemas de informações nesta área focam a atualização dos registros de estoque, geração de pedidos, geração de relatórios de status de estoque e previsão de demanda (SLACK, 1996).

Ao designar clientes a veículos ou rotas, o gerente tem o desafio de maximizar suas economias, portanto, cada cliente é designado a uma rota separada, inicialmente. Contudo, caso o total de entregas não exceda a capacidade o veículo, duas rotas podem ser combinadas em uma rota exeqüível. No intuito de minimizar a distância que cada veículo deve percorrer, o gerente deve criar a seqüência de clientes dentro das rotas (CHOPRA e MEINDL, 2003).

A roteirização de veículos é analisada por três fatores fundamentais, sendo eles decisões, objetivos e restrições. Segundo NOVAES (2003), a roteirização pode ocorrer sem restrições por meio do método de construção de roteiro ou de melhoria do roteiro. Caso a definição da roteirização seja com restrições por limites de tempo ou de capacidade do veículo, são apresentados dois métodos matemáticos, sendo eles o de varredura e o de Clarke e Wright. Na distribuição física de produtos, os impactos das restrições de tempo de capacidade nem sempre é bem entendida no momento de planejar um sistema de entregas de produtos.

Para BALLOU (1993), o planejamento do suprimento e distribuição física de qualquer firma é a soma de planos individuais dos produtos que podem estar em diferentes pontos do seu ciclo de vida e com variados graus de sucesso comercial, e este fenômeno denomina-se a curva ABC. O critério ABC para os estoques é um método de itens de estoque de uma empresa e classificação em grupos de itens, sob o ponto de vista econômico-financeiro, de acordo com suas importâncias relativas. A classe A apresenta 5\% dos itens e um percentual de demanda em valores monetários igual a $70 \%$; a classe B destaca $20 \%$ dos itens e um percentual da demanda de valores monetários igual a $25 \%$; e a classe C compreende $70 \%$ dos itens e um percentual da demanda em valores monetários igual a 5\% (JACOBSEN, 2003). 


\section{Metodologia}

Esta pesquisa realizou um estudo de caso com abordagem qualitativa, que "possibilita a penetração na realidade social, não conseguida plenamente pela análise e pela avaliação quantitativa" (MARTINS e LINTZ, 2000). No entanto, não são permitidas generalizações para o estudo de caso, segundo YIN (1994).

A unidade de análise, segundo POZZEBON e FREITAS (1997), "pode ser composta por indivíduos, grupos ou organizações, ou ainda por projetos, sistemas ou processos decisórios específicos". O estudo de caso apresentado foi realizado em uma distribuidora de medicamentos em Juiz de Fora/MG que está presente no mercado desde 1978.

YIN (1994) defende que o estudo de caso é uma forma de se fazer pesquisa empírica que investiga fenômenos contemporâneos dentro de seu contexto de vida real, em situações em que as fronteiras entre o fenômeno e o contexto não estão claramente estabelecidas e nas quais se utilizam múltiplas fontes de evidência. Para tanto, foram empregadas as técnicas de entrevista, análise documental e observação não-participante.

A observação não participante, para ALENCAR (1999), é um instrumento muito importante quando se pretende compreender uma determinada realidade social em que os fatos, valores, razões e idéias não são sempre expressos verbalmente. A observação não participante é aquela na qual o pesquisador permanece no local onde os indivíduos estão sendo observados, no entanto, não se faz passar por um deles.

O instrumento de pesquisa utilizado para a realização das entrevistas foi o questionário semiestruturado. O questionário semi-estruturado pode ser formado por questões abertas padronizadas ou roteiro de assuntos. Sendo que, a forma da entrevista é apresentada a partir do entrevistado. A entrevista semi-estruturada, para TRIVIÑOS (1994), é um dos "instrumentos mais decisivos para estudar os processos e produtos nos quais está interessado o investigador qualitativo". ALENCAR (2000) afirma que "a vantagem deste tipo de questionário é permitir que o entrevistado manifeste suas opiniões, seus pontos de vista e seus argumentos".

As entrevistas foram realizadas com várias pessoas na distribuidora: diretor; vice-diretor; e gerentes de estoque, transporte, compras, telemarketing e processamento de dados. A análise das entrevistas utilizou a análise de conteúdo, definida por BARDIN (1977) como um 
conjunto de técnicas que visa obter um método sistemático com o objetivo de descrever o conteúdo das mensagens para inferir sobre conhecimentos relativos às condições de produção/recepção.

\section{$4 \quad$ Resultados e Discussão}

\subsection{Caracterização da Empresa}

A empresa em estudo é um atacado e sua sede está situada em Juiz de Fora, Minas Gerais. O ramo de atuação da empresa em estudo é a comercialização de produtos para farmácias, na linha de medicamentos e perfumaria. Os clientes fazem a compra com a distribuidora por meio do serviço de telemarketing. Existem representantes de vendas que visitam as farmácias freqüentemente, mas os pedidos são todos realizados por meio do serviço de telemarketing que utiliza uma linha de ligação gratuita para o cliente, 0800 .

O serviço de telemarketing atua de forma ativa e receptiva, portanto, este setor atua como televendas e recebe pedidos de compra. O valor mínimo do pedido conforme recomenda BALLOU (1993), foi definido pela distribuidora em cento e cinqüenta reais, no entanto, este valor pode ser referente a apenas um produto. Esta política foi estipulada para que pudesse reduzir o número de pedidos e ter economia com transporte e atendimento.

A empresa contém no quadro de funcionários oito motoristas; dois ajudantes de viagem; um chefe de transporte; um vigia; uma servente; onze conferentes; três separadores de medicamentos; uma recepcionista; e três funcionários que atuam em atividades de escritório. Além destes funcionários a empresa tem um funcionário na atividade de compra; um funcionário de serviços gerais, um farmacêutico e três funcionários no centro de processamento de dados.

O telemarketing, que atua também como televendas, tem uma funcionária que trabalha de 8 às 14 horas; e outra funcionária de 9 às 15 horas; as outras três funcionárias de telemarketing trabalham das 15 às 21 horas. Os funcionários conferentes trabalham das 13 às 22, com uma hora de lanche e atuam no estoque. No centro de processamento de dados e na recepção, o horário é comercial. Os entregadores dos medicamentos são os próprios motoristas e eles iniciam o expediente de trabalho às seis horas, porque carregam os carros, antes de sair para entrega. Quando a entrega termina, os motoristas encerram o horário de trabalho e retornam à 
empresa no outro dia de manhã, quando tem acesso à escala de viagem e carregam os veículos novamente.

\subsection{Controle de Estoque}

O gerente de estoque, afirma que quando os produtos são retirados, estes são computados como saída do produto no sistema de gestão da distribuidora. No entanto, é feita uma auditoria de contagem de produtos para comparar o estoque real com o estoque computado no sistema de gestão da distribuidora. Esta contagem ocorre de 30 em 30 dias. Não existe uma quantidade mínima de produto no estoque, conforme recomenda a Curva Dente de Serra, expressa por SLACK et al. (1996) e DIAS (1995). O gerente de estoque afirmou que às vezes o produto acaba e não existem pedidos para este, sendo preciso esperar a entrega pelo laboratório farmacêutico. Percebe-se que esta atitude é arriscada e possibilita riscos de comercialização, pois as farmácias que podem realizar um pedido e não o obterem por falta de produto em estoque. Diante da concorrência do setor, o cliente dirige-se a outro distribuidor que tenha produto, distanciando o relacionamento com a distribuidora por esta não ter atendido o pedido; e usufruindo o relacionamento com o concorrente da distribuidora.

No setor farmacêutico, os medicamentos apresentam variações da demanda. Considerando as demandas apresentadas por BALLOU (1993), estas podem ser: permanentes (medicamentos de uso contínuo, por exemplo: insulina); irregulares (medicamentos de procura espontânea, ou seja, que não necessitam de prescrição médica); sazonais (medicamentos que variam de acordo com a variação da temperatura, por exemplo, pois as pessoas são mais propensas a terem resfriados e doenças pulmonares nestas épocas); em declínio (medicamentos que perderam a patente e atualmente possuem vários concorrentes com preços inferiores); e derivada (por exemplo, medicamentos para tratar os sintomas da dengue, pois só são consumidos porque existe a epidemia). O tipo de estoque, segundo definição de SLACK et al. (1996), da distribuidora farmacêutica é o estoque de antecipação, que é utilizado para compensar diferenças de ritmo entre fornecimento e demanda.

O arranjo físico do depósito da distribuidora não apresenta uma organização definida, no entanto, assemelha-se mais aos critérios de localização por produto, apresentado SLACK et al. (1996). Os produtos são organizados pelo endereço, ou "apartamento/prédio". Ou seja, o produto é registrado em um livro, e neste livro registra-se o endereço da localização na qual está disposto o medicamento. Portanto, é necessário pesquisar no livro que apresenta os 
medicamentos em ordem alfabética e localizar que o medicamento está localizado, por exemplo, na $1^{\text {a }}$ seção, na coluna 9. O critério estabelecido para alocar os produtos nas prateleiras é variável e o sistema de codificação adotado é o alfanumérico.

Segundo o gerente de estoque, "às vezes identifica-se os produtos de acordo com a saída das mercadorias, e também, separa-se medicamento líquido de medicamento que é pomada, para não confundir". Os remédios controlados são alocados em local reservado, em uma parte do depósito que está sempre fechada. Apenas uma pessoa tem acesso aos medicamentos controlados. E ainda, existem os medicamentos que precisam de refrigeração, estes ficam em uma geladeira com temperatura controlada. Diante desta descrição, percebe-se que o sistema de estocagem poderia ser classificado como fixo, segundo DIAS (1995), caso o gerente de estoque não tivesse utilizado o termo "às vezes". Pela forma de exposição utilizada é mais conveniente classificar o sistema de estocagem como livre, pois os produtos de estocagem especial realmente são reservados em áreas específicas e seguem um procedimento fixo.

O controle da validade dos medicamentos é feito pelo lote de entrada. Ao ser questionado sobre o controle de validade dos medicamentos, o gerente do estoque afirmou que não tem estes dados no computador, sendo todo o controle feito manualmente. Cada funcionário circula na seção e acompanha a validade dos medicamentos enquanto realiza o serviço de selecionar os medicamentos constantes no pedido. Como forma de prevenir a perda de medicamentos, quando é realizada a entrada mercadoria nova, coloca-a atrás da mercadoria já armazenada.

Em virtude do controle de estoque, quando o medicamento está com a data de validade próxima, normalmente um mês ou dois meses antes, o medicamento é retirado do estoque e é realizada sua devolução quando o laboratório aceita, mas muitos laboratórios não aceitam devolução, segundo o gerente de estoque. Caso o medicamento não seja aceito pelo laboratório, a distribuidora informa à prefeitura sobre a validade do medicamento e solicita que esta realize a coleta dos medicamentos nas instalações da distribuidora para descartar o medicamento junto à vigilância sanitária. Percebe-se que o sistema de informações da distribuidora poderia apresentar informação de que o produto ainda está no estoque da distribuidora com data de validade próxima ao vencimento. Desta forma, com planejamento adequado seria possível uma maior assertividade à distribuidora, reduzindo as perdas de estoque por vencimento da validade. 
O gerente de estoque estima que para um funcionário novo adaptar-se ao setor, da forma como o estoque está organizado, transcorre um período de 5 a 10 meses. Anteriormente, a distribuidora adotava como critério para armazenar os produtos, a separação por laboratório. O gerente de estoque considera que era mais fácil associar a organização do estoque pelo laboratório, porque se sabia onde encontrar o produto de forma mais ágil. A forma atual não permite uma rápida associação do produto ao local onde está armazenado, mas é menos arriscada; pois "por laboratório, vai indo as vistas ficam cansadas e você troca, não tem jeito, então pra evitar isso, passou a ser guardado desse jeito".

Com relação às falhas existentes na seleção do produto, o gerente de estoque, justifica que "o ser humano é falho em alguns instantes". A distribuidora utiliza o processo de conferência para garantir que os medicamentos separados estão de acordo com os medicamentos solicitados. Anteriormente, um outro funcionário realizava a conferência, hoje o funcionário que separa o material é quem realiza a conferência. Com esta alteração, o gerente de estoque percebeu que o número de erros na seleção dos medicamentos reduziu consideravelmente, porque o funcionário é responsável pela seleção e conferência dos medicamentos.

O estoque dos medicamentos é separado do estoque da perfumaria, portanto, para a finalização da seleção dos pedidos é necessário unir o que foi selecionado em cada estoque. Após este processo, o pedido é separado por rota de entrega da mercadoria.

\subsection{Análise do Cenário Logístico}

O vice-presidente da distribuidora considera que a maior exigência dos clientes é a pontualidade na entrega. Quando a entrega é realizada com atraso, os clientes não recebem a mercadoria, pois outras empresas oferecem o mesmo tipo de serviço. Portanto, a prestação do serviço da distribuidora, que se inicia com o recebimento do pedido e prossegue até a entrega, precisa ser ágil e precisa.

A frota disponível da distribuidora é de sete carros, quatro Fiorino (Furgão), duas Besta, e uma Kombi que só realiza a rota da praça, ou seja, da cidade de Juiz de Fora. Todos os veículos da distribuidora são assegurados, no entanto a carga não é assegurada. Neste ramo de atuação é freqüente o furto de carros de entrega, por isto, os carros da frota não apresentam sinalização de que são de uma distribuidora de medicamentos. 
A rota de entrega é definida após findar a recepção de pedidos, portanto, às vezes esta é definida após as nove horas da noite ou às cinco horas da manhã do dia seguinte. No entanto, as rotas já são fixas e define-se apenas em qual das farmácias da rota necessita ser feita a entrega. Mas, de acordo com o volume da carga, a entrega é organizada para que seja feito o menor deslocamento possível, reduzindo veículos e permitindo que a carga chegue mais cedo. $\mathrm{Na}$ distribuidora, todo este processo de tomada de decisão é feito sem um sistema para suporte à decisão. A utilização de um sistema para geração de uma sugestão das rotas a serem realizadas seria de grande utilidade para redução do tempo de trabalho do responsável pela definição das rotas a serem realizadas.

Para não danificar a carga no transporte a distribuidora dedica-se a embalar de forma adequada os medicamentos. A organização dentro do veículo de entrega é feita de acordo com a rota. Sendo assim, a última entrega é colocada no carro de forma a não mexer nesta. Desta forma, no momento da entrega dos medicamentos às farmácias, o motorista necessita apenas abrir a porta e retirar a embalagem para a farmácia, cuja identificação é sinalizada no exterior da embalagem por meio do número do pedido e do nome da farmácia.

No momento em que é realizada a entrega dos medicamentos, o motorista não aguarda o responsável da farmácia conferir os medicamentos entregues. Esta falta de acompanhamento possibilita que algumas farmácias não tenham uma atitude idônea, e afirmem que o pedido não foi entregue com todos os medicamentos, finalizando no furto de medicamentos da distribuidora. Uma vez que a distribuidora não tem possibilidades de confirmar que todos os produtos solicitados foram entregues adequadamente, pois apenas um conferente realiza a separação do pedido.

O chefe dos transportes sabe o posicionamento da entrega durante o decorrer do dia por meio do roteiro de entrega, mas os motoristas não têm comunicação com o gerente de transporte, eles apenas se comunicam quando existem imprevistos que prejudiquem a entrega. A distribuidora não tem um sistema de comunicação com os motoristas que entregam os pedidos. Portanto, se a distribuidora precisar falar às 10 horas da manhã com o motorista, o recurso disponível é efetuar ligações para as farmácias e perguntar se a entrega já foi realizada. Caso não tenha sido realizada, a distribuidora deixa um recado pedindo para o motorista ligar para a distribuidora. 
Ao findar a entrega, os motoristas retornam para Juiz de Fora e levam os carros para casa, porque tem problemas com horário de ônibus, para estar no pátio da distribuidora no dia seguinte. A conferência das entregas realizadas é feita por meio do canhoto da nota fiscal, entregue no dia seguinte, quando o motorista recebe o roteiro do dia e coleta as mercadorias para entrega.

O presidente da distribuidora tem conhecimento de que os seus concorrentes utilizam serviço terceirizado para a entrega de produtos, no entanto, não executa o trabalho da distribuidora por intermédio de uma empresa terceirizada porque a distribuidora obteve uma experiência traumática, um tempo atrás, com uma empresa terceirizada nesta área. O vice-presidente da distribuidora afirma que até pouco tempo a distribuidora terceirizava o serviço de entrega, mas esta ficou deficitária em seu serviço, pois ao invés de entregar na hora, estava sendo necessário esperar. Os operadores logísticos disponíveis na região eram da cidade de Leopoldina e do Rio de Janeiro. Então, para facilitar, a distribuidora dirigia-se até Leopoldina com um carro e deixava parte da entrega; e logo após o veículo da distribuidora seguia até o estado do Rio de Janeiro e entregava a uma outra empresa terceirizada as mercadorias a serem entregues.

O processo de entrega da distribuidora difere das suas concorrentes no mercado em alguns pontos. Segundo o gerente de vendas da distribuidora, "algumas coisas são diferenciadas porque os concorrentes não entregam as mercadorias pela própria empresa, elas terceirizam”. O gerente de vendas, ao ser abordado sobre o impacto do sistema de terceirização no relacionamento com o cliente considera que a terceirização é bem vinda; em suas palavras: “_Nós não sabemos ler remédio, quanto mais entregar".

A distribuidora não realiza uma diferenciação por cliente, sendo assim todos os clientes são considerados da mesma forma. Segundo o gerente de transportes, com a atual organização de entrega dos pedidos da distribuidora, os clientes são atendidos até as duas horas da tarde do dia seguinte. Para o gestor logístico não é interessante roteirizar por cliente, porque o importante é agilizar a entrega e atender a todos os clientes, pois "o risco de estar sem o seguro da carga é o mesmo". Já para a entrega em Juiz de Fora, não existe uma rota definida. A entrega é feita três vezes ao dia e a intenção é atender imediatamente o cliente, independente de sua representatividade atual para a distribuidora. 
O vice-presidente da distribuidora relata que no caso dos transportes, um controle mais rígido está sendo executado. As inovações inseridas para o controle permitem que a distribuidora tenha um controle da rota, ou seja, que se saiba para onde vai o carro, quantos quilômetros ele roda, e em que horário vai estar no lugar determinado. Às segundas-feiras, dois dos veículos da frota são submetidos à revisão; pois, na segunda-feira a entrega é menor, devido à compra de sexta-feira ser entregue no sábado e no sábado não existir um grande número de pedidos.

A distribuidora passou recentemente por um processo de enxugamento do número de medicamentos comercializado. $\mathrm{O}$ vice-presidente considera que não adianta ter 2 milhões de mercadorias e entregá-las aleatoriamente. Este enxugamento contribuiu para gerar uma melhor percepção de qual medicamento usualmente comprado tem saída efetiva; pois ocorre do comprador ter o hábito de manter estoque acima do ponto ótimo para a distribuidora, e desta forma o estoque apresentava muitos produtos que não são usualmente vendidos. Para o vice-presidente, em função do melhor atendimento dos clientes, os pedidos que são efetuados, acusam se haverá mercadoria ou não em estoque por meio do saldo diário dos medicamentos.

O responsável pelas compras da distribuidora utiliza um sistema de informações para basearse no momento de realizar as compras. Para tomar a decisão de compra, este analisa o produto e sua demanda, considerando o volume em estoque e o volume de venda no mês, ou no período. O sistema de informações permite que sejam realizadas simulações, pois quando é aberta a tela do computador, o funcionário digita a posição que deseja e é apresentado o volume para compra em 10, 15 ou 30 dias. Além destes dados apresenta-se um prazo de entrega e o volume de estoque. A partir destas informações, torna-se disponível na tela a situação do produto, o estoque, o preço, e uma sugestão de compra. No entanto, o responsável pelas compras afirmou que não faz uso constante das informações do sistema.

\section{Conclusão}

Este trabalho descreveu o processo logístico de distribuição e controle de estoque de uma distribuidora de produtos para farmácias, na linha de medicamentos e perfumaria. E ainda, realizou uma análise sobre a sua forma de atuação, propondo melhorias para a realização das mesmas. O resultado desta pesquisa qualitativa foi contemplado pela distribuidora de medicamentos, no intuito de melhorar a sua atuação no mercado. Para tanto, descreveu-se o processo logístico e a gestão de estoque da distribuidora. 
Sobre o controle de estoque, o arranjo físico do depósito da distribuidora não apresenta uma organização definida. No entanto, assemelha-se aos critérios de localização por produto, apresentado por SLACK et al. (1996). Os remédios controlados são alocados em local reservado, em uma parte do depósito que permanece fechada. E ainda, os medicamentos que precisam de refrigeração ficam em uma geladeira com temperatura controlada. Portanto, o sistema de estocagem, pode ser considerado livre, pois os demais medicamentos não apresentam uma ordem fixa de disposição.

A distribuidora apresenta uma frota própria e não tem interesse na atuação com gestores logísticos terceirizados. A organização dentro do veículo de entrega é feita de acordo com a rota. Sendo assim, a última entrega é colocada no fundo do veículo, para o motorista não necessitar alterar a carga de lugar até a chegada no destino. Este procedimento otimiza o tempo de entrega, pois, no momento da entrega às farmácias, o motorista necessita apenas abrir a porta e retirar a embalagem para a farmácia. A identificação é sinalizada no exterior da embalagem por meio do número do pedido e do nome da farmácia.

Como resultados, identificou-se que a distribuidora utiliza o sistema de distribuição um para muitos, organiza o estoque de produtos por produto e não terceiriza o serviço de entrega. Afirma-se ainda que a distribuidora necessita da utilização de um sistema de informação que permita melhor integração entre os setores da empresa. Percebeu-se que a distribuidora precisa promover formas de mais bem utilizá-lo; principalmente para a área de compras, que não estão sendo utilizadas com eficiência. Considera-se ainda que o sistema pode ser ampliado contemplando interfaces e ferramentas que auxiliem no controle de estoques e na definição da rota de entrega.

As propostas de melhoria advindas do estudo de caso para a empresa consistem na análise de um arranjo físico de estoque mais prático para a adaptação de novos funcionários, da melhoria de comunicação com os motoristas que realizam as entregas e do aumento da vantagem competitiva por meio da integração de sistemas.

Os distribuidores apresentam uma relevante participação entre os canais de marketing do setor farmacêutico, principalmente, porque apresentam utilidades de tempo, lugar e posse aos canais do varejo em que atua, ou seja, às farmácias. No entanto, recentemente, têm existido freqüentes fusões entre os atacadistas do setor farmacêutico, o que modifica a atuação destes. Considera-se ainda que este agente do canal de marketing sofre constante redução das 
margens de contribuição dos medicamentos e necessita agregar valor para ser necessário no mercado. Portanto, o distribuidor deve buscar adquirir know how para deixar de ser estocador de mercadorias e buscar agir como comercializador dos produtos farmacêuticos que incorpore funções de operador logístico com parcerias de relacionamento próximas.

Este trabalho permitiu identificar o processo logístico de uma distribuidora de medicamentos e identificar pontos do sistema de informações que podem ser mais bem trabalhados no intuito de contribuir para a eficiência e eficácia do sistema logístico da distribuidora de medicamentos. Considera-se que estudos do gênero são relevantes para que os tomadores de decisão tenham mais perspectivas em relação ao mundo corporativo.

\section{Referências Bibliográficas}

ALENCAR, E. Introdução à metodologia de pesquisa social. Lavras: UFLA/FAEPE, 1999.

BALLOU, R. H. Gerenciamento da Cadeia de Suprimentos: planejamento, organização e logística empresarial. Tradução de Elias Pereira. 4. ed. Porto Alegre: Bookman, 2001.

BALLOU, Ronald H. Logística Empresarial: transportes, administração de materiais e distribuição física. São Paulo: Atlas, 1993.

BARDIN, Laurence. Análise de conteúdo. São Paulo: Livraria Martins Fontes, 1977.

CHOPRA, Sunil; MEINDL, Peter. Gerenciamento da Cadeia de Suprimentos. São Paulo: Prentice Hall, 2003.

CHRISTOPHER, Martin. Logística e gerenciamento da cadeia de suprimentos: estratégias para a redução de custos e melhoria dos serviços. 1. ed. São Paulo: Pioneira, 1997.

COUGHLAN, A. T.; ANDERSON, E.; STERN, L. W.; EL-ANSARY, A. L. Canais de marketing e distribuição. 6. ed. São Paulo: Bookman, 2002.

DIAS, Marco Aurélio P. Administração de Materiais. Edição Compacta. $4^{\mathrm{a}}$ ed. São Paulo: Atlas, 1995.

HARRISON, Alan; HOCK, Remko Van. Estratégia e gerenciamento de logística. São Paulo: Futura, 2003.

JACOBSEN, Mércio. Logística Empresarial. Itajaí: UNIVALI, 2003. 
KOTLER, P. Administração de Marketing: a edição do novo milênio. 10 ed. Tradução de Bazán Tecnologia e Lingüística. São Paulo: Prentice Hall, 2000.

KOTLER, Philip; ARMSTRONG, Gary. Princípios de Marketing. 7 ed. Rio de Janeiro: LTC, 1999.

LOURENÇO, Fátima. Uma nova receita. Rio de Janeiro: Pequenas Empresas Grandes Negócios, n. 137, jun. 2000.

MARTINS, G. A ; LINTZ, A. Guia para elaboração de monografias e trabalhos de conclusão de curso. São Paulo: Atlas, 2000.

NOVAES, Antônio Galvão. Logística e Gerenciamento da Cadeia de Distribuição: estratégia, operação e avaliação. Rio de Janeiro: Campus, 2001.

PARENTE, Juracy. Varejo no Brasil: Gestão e Estratégia. São Paulo: Atlas, 2000.

POZZEBON, Marlei, FREITAS, Henrique M. R. de. Por um conjunto de princípios que possibilitem a construção de novos modelos de sistemas de informação. Revista de Administração Pública, Rio de Janeiro: v. 31, n. 5, p. 87-104, set./out. 1997.

REIS, Manoel de Andrade e Silva. O DESAFIO da logística. Intermanagers. São Paulo, 07 jul. 2000. Disponível em: < http://www.intermanagers.com.br $>$. Acesso em: 31 ago. 2002.

RODRIGUES, Gizela Gonzaga; Nélio Domingues PIZZOLATO. Centros de distribuição: armazenagem estratégica. Anais eletrônicos do XXIII ENEGEP - Encontro Nacional de Engenharia de Produção. Ouro Preto, 2003.

ROSENBLOOM, Bert. Canais de Marketing: uma visão gerencial. 1. ed. São Paulo: Atlas, 2002.

SIMCHI-LEVI, David; KAMINSKY, Philip; SIMCHI-LEVI, Edith. Cadeia de suprimentos: projeto e gestão. Tradução: Marcelo Klippel. Porto Alegre: Bookman, 2003.

SLACK, N.; CHAMBERS, S.; HARLAND, C.; HARRISON, A.; JOHNSTON, R. Administração da Produção. São Paulo: Atlas, 1996.

TRIVIÑOS, A.S. Introdução à pesquisa em ciências sociais. São Paulo: Atlas, 1994. 
VERÍSSIMO, Nádia; MUSETTI, Marcel Andreotti. A tecnologia de informação na gestão de armazenagem. Anais eletrônicos do XXIII ENEGEP - Encontro Nacional de Engenharia de Produção. Ouro Preto, 2003.

YIN, Robert K. Estudo de caso: planejamento e métodos. $2^{\text {a }}$ ed. São Paulo: Bookman, 1994.

Artigo Recebido em 04/11/2003 e aceito para publicação em 15/09/05. 